\section{Vehicle Speed Estimation Using Computer Vision And Evolutionary Camera Calibration}

Hector Mejia1, Esteban J. Palomo², Ezequiel López-Rubio², Israel Pineda1, Rigoberto Fonseca-

${ }^{1}$ School of Mathematical and Computational Sciences, Yachay Tech University ${ }^{2}$ Department of Computer Languages and Computer Science, University of Malaga Department of Electrical Engineering, Metropolitan Autonomous University

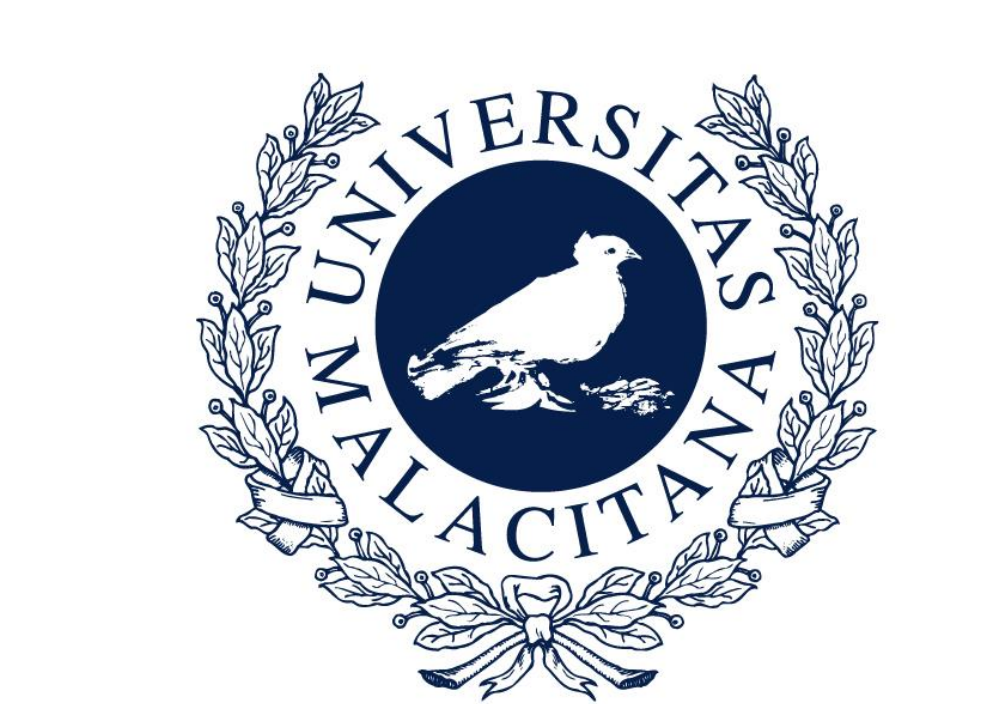

UIVERSIDAD DE MÁLAGA

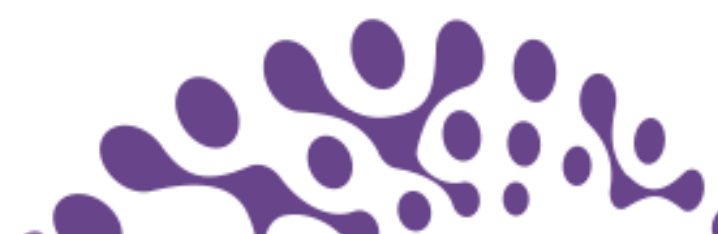

NEURAL INFORMATION PROCESSING SYSTEMS

UNIVERSIDAD

YACHAY

TECH

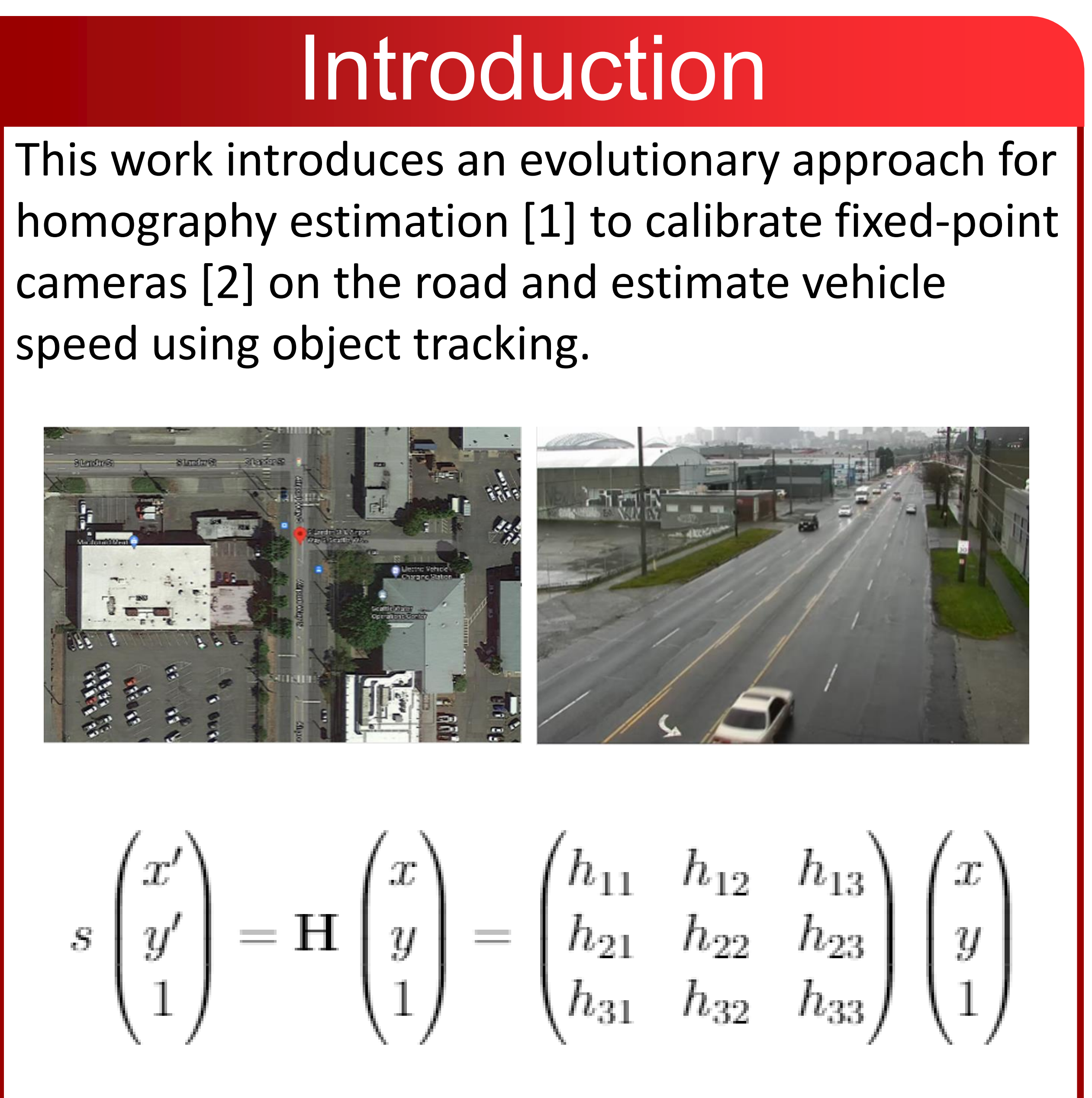

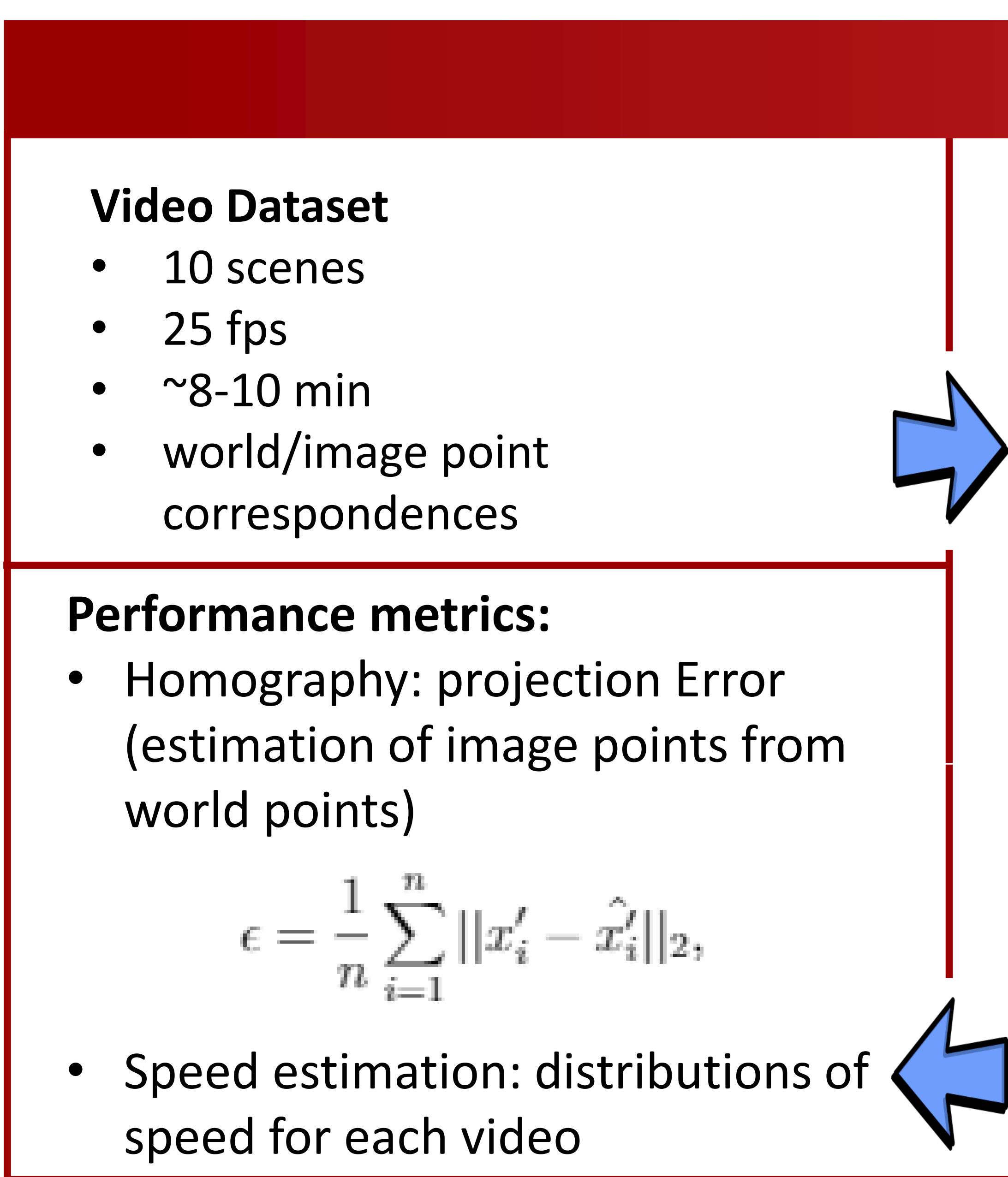

speed for each video

\title{
Methodology
}

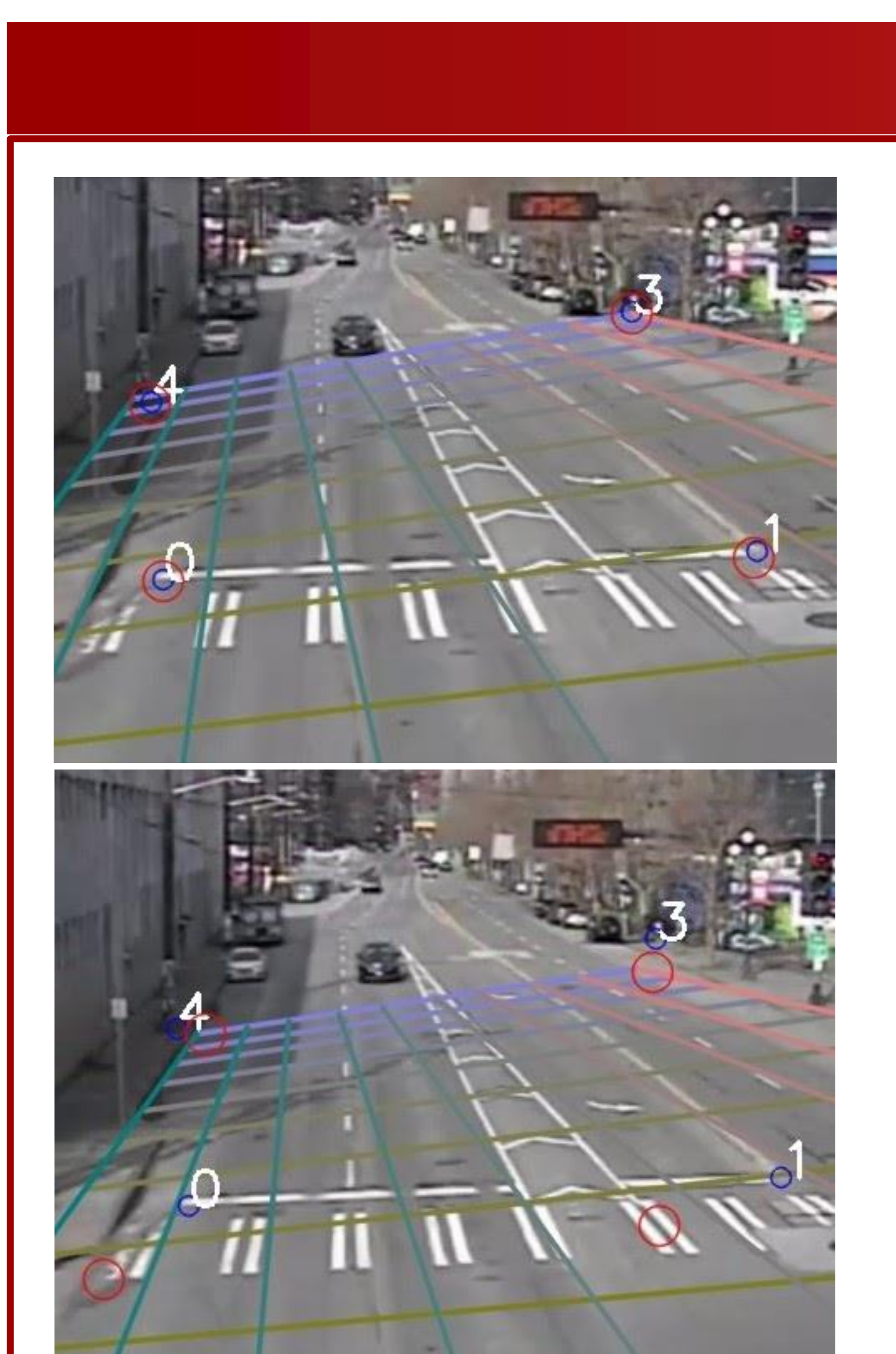

Contact:

Hector Mejia Vallejo

mail: mejia_vallejo@hotmail.com hice speed estimation
hithon

\section{Results}

Graphical comparison

of the calibrations

Proposed evolutionary DLT

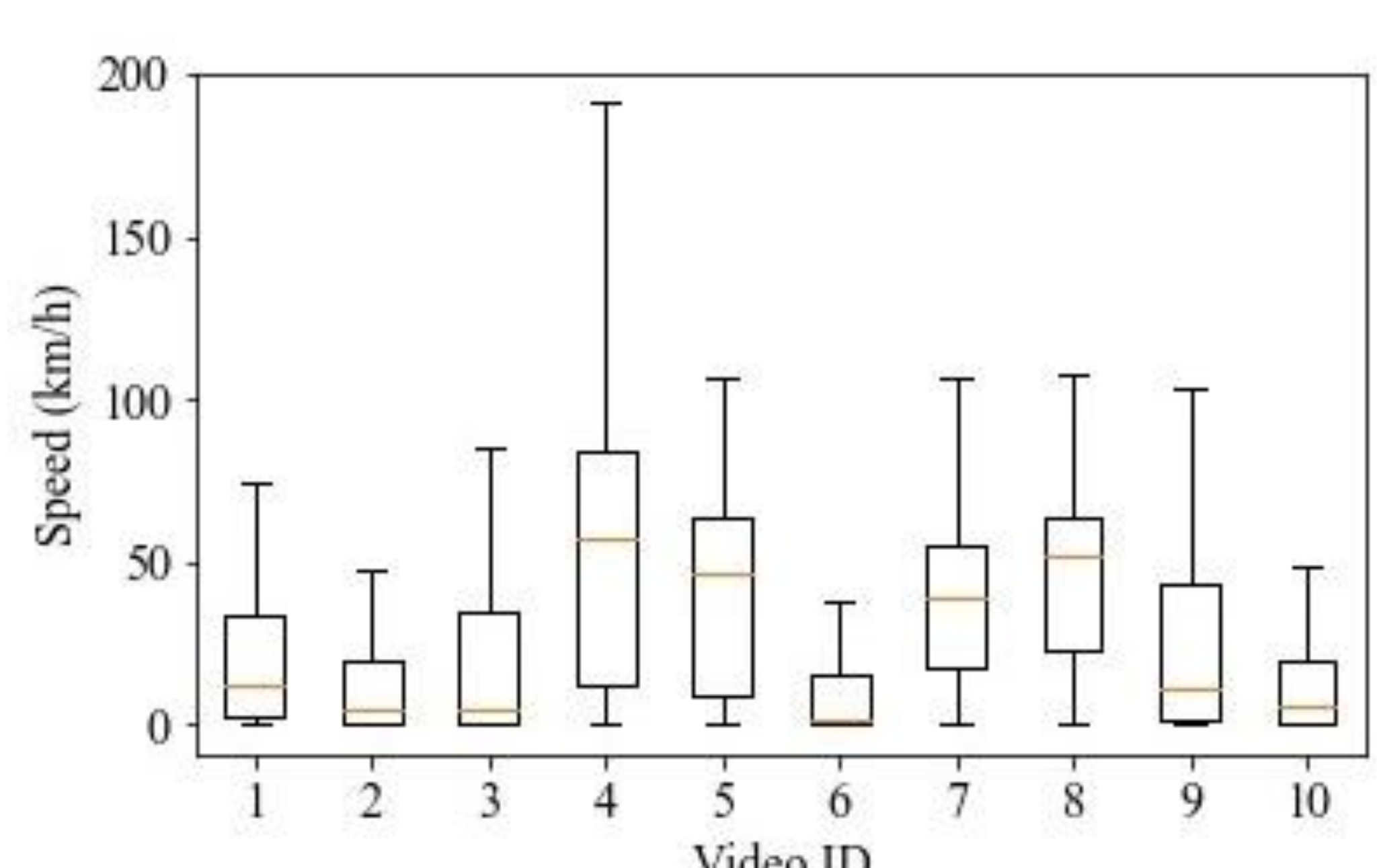

Distributions of speed for all the videos Base DLT

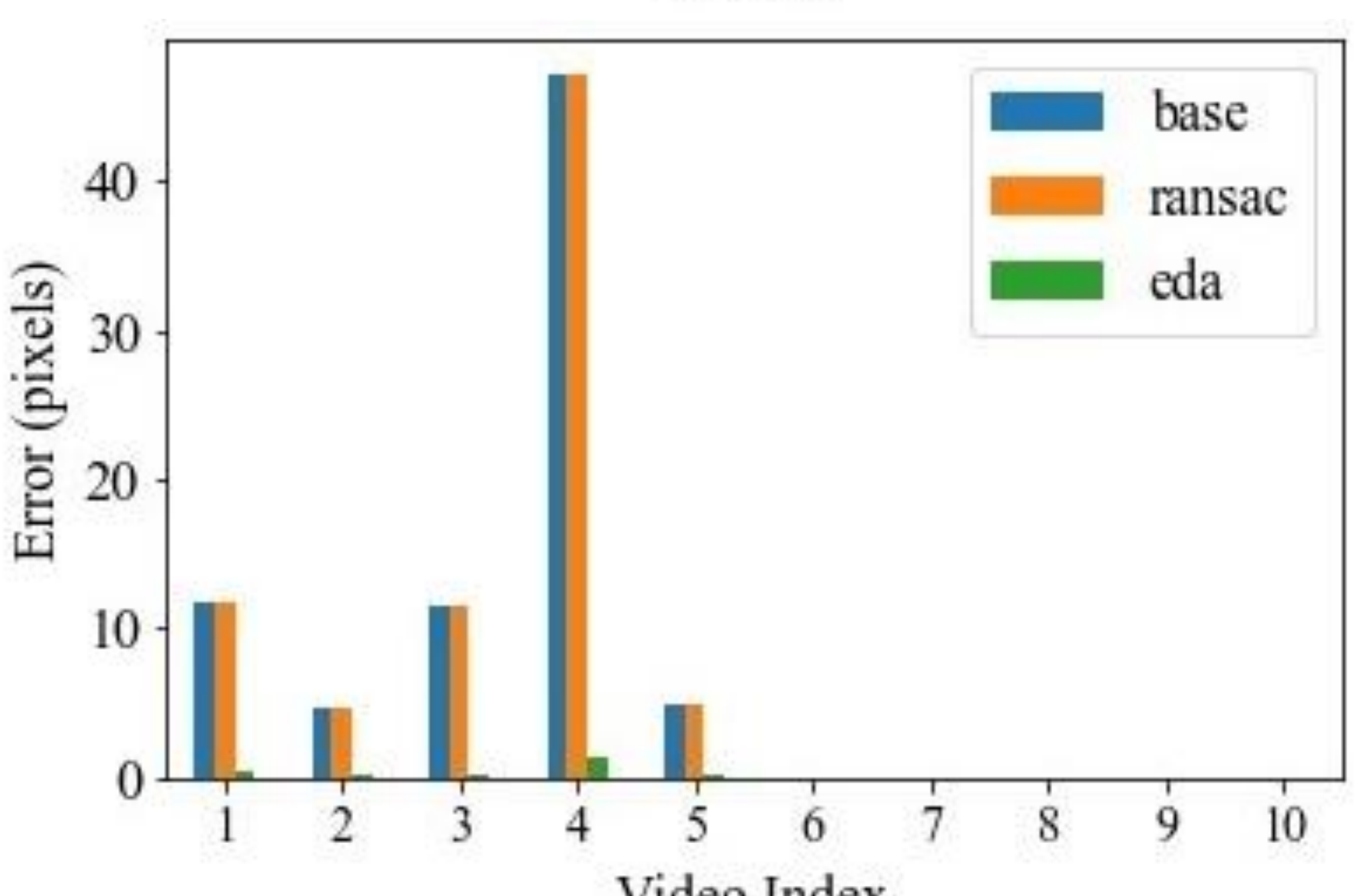

Projection error for the evaluated homography estimation methodologies

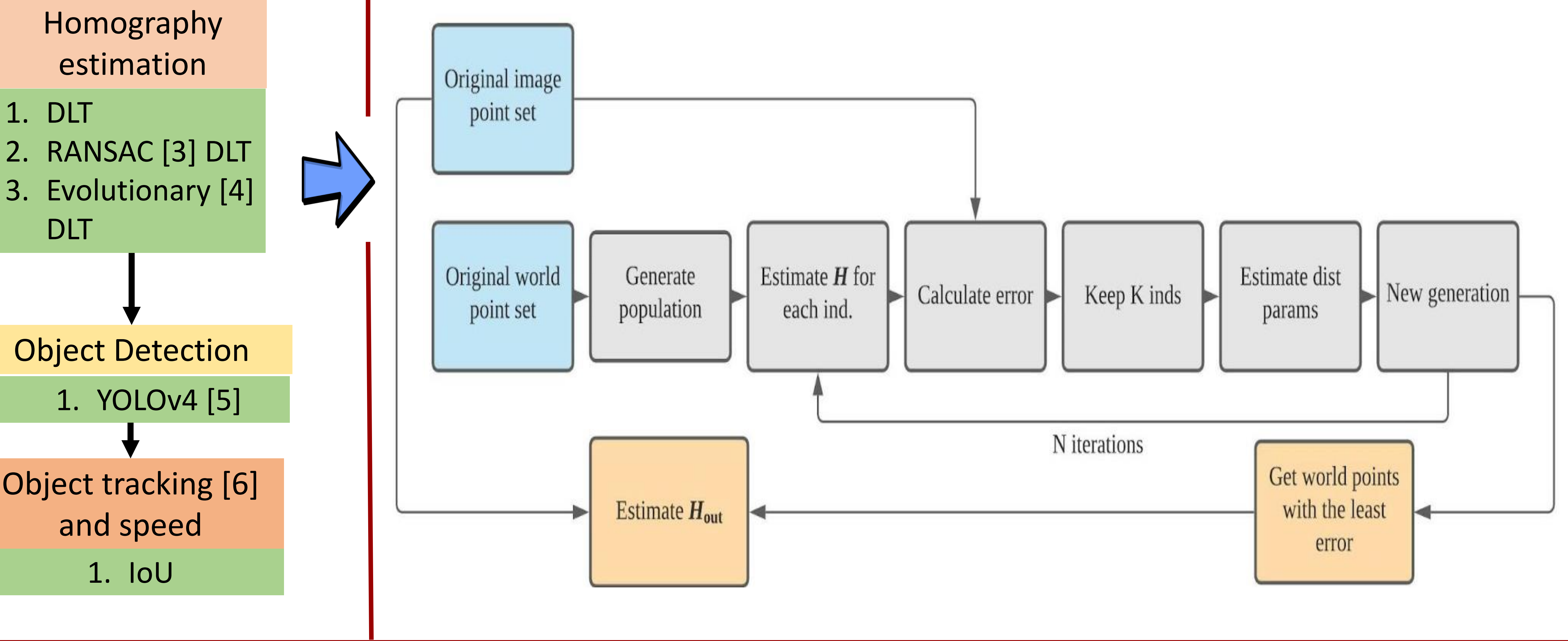

Conclusions

Both RANSAC and base algorithms got an error of 7.99 pixels, while the proposed returned only 0.24 . This represents a reduction of $97 \%$ in projection error.

2. Most speed values are less than $70 \mathrm{~km} / \mathrm{h}$. The speed estimation distributions along with the vehicles speed timeseries resembled the behavior of drivers on an urban city.
Independent for 10
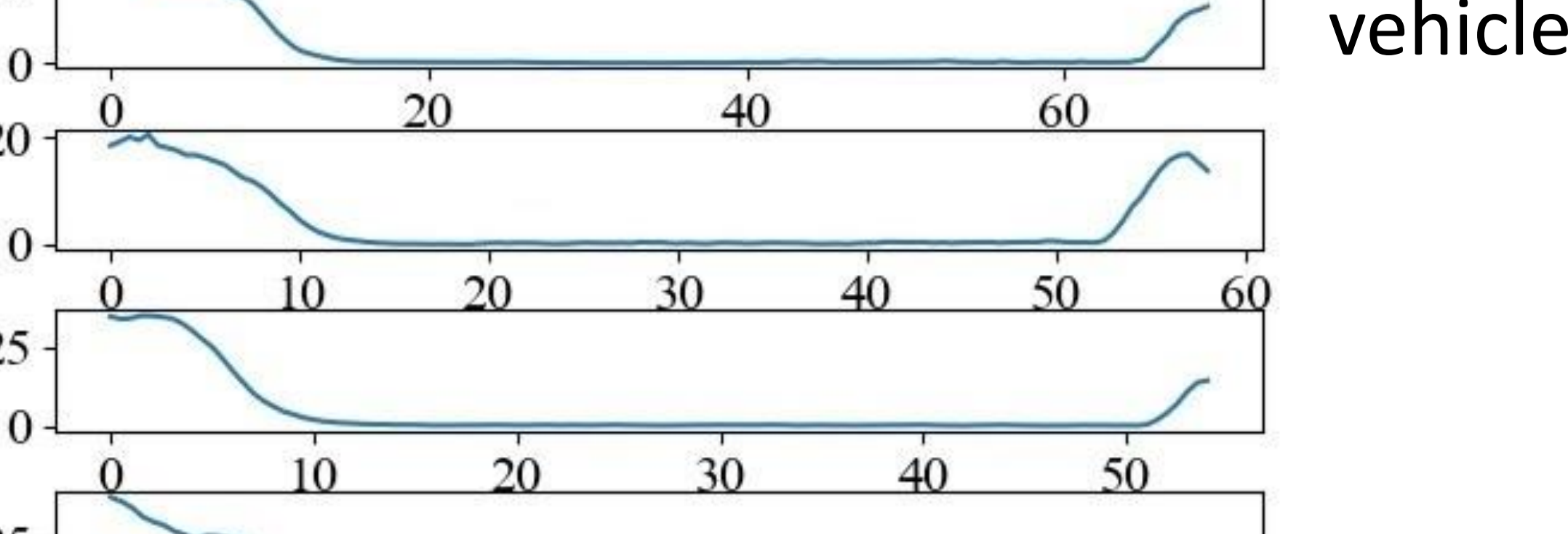

25

\section{References}

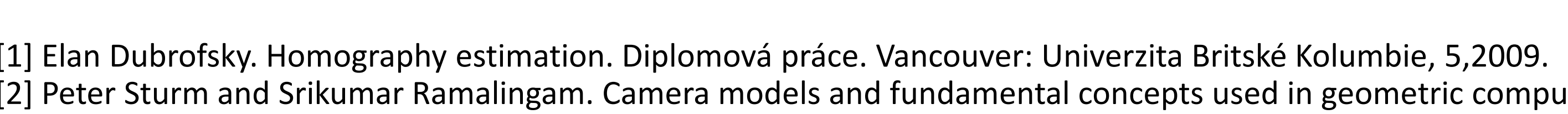

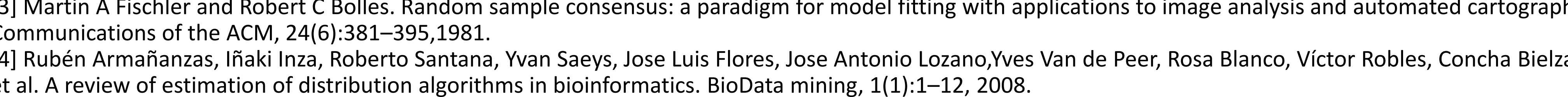

